\title{
RATIONALE AND RESULTS OF PROXIMAL HUMERUS FRACTURE FIXATION
}

\author{
Kishore Kannan"1, Mathivanan Palaniappan², Srinivasan Anbu³, Kalyanasundaram Kolundan4, Ramesh Prabu Ganesan', \\ Subramanian Karunanithi ${ }^{6}$
}

\begin{abstract}
${ }^{1}$ Assistant Professor, Department of Orthopaedics, KAPV Govt. Medical College/MGM Govt. Hospital, Tiruchirapalli. 2Professor, Department of Orthopaedics, KAPV Govt. Medical College/MGM Govt. Hospital, Tiruchirapalli. ${ }_{3}^{3}$ Associate Professor, Department of Orthopaedics, KAPV Govt. Medical College/MGM Govt. Hospital, Tiruchirapalli. ${ }^{4}$ Associate Professor, Department of Orthopaedics, KAPV Govt. Medical College/MGM Govt. Hospital, Tiruchirapalli. ${ }^{5}$ Assistant Professor, Department of Orthopaedics, KAPV Govt. Medical College/MGM Govt. Hospital, Tiruchirapalli. ${ }^{6}$ Assistant Professor, Department of Orthopaedics, KAPV Govt. Medical College/MGM Govt. Hospital, Tiruchirapalli.
\end{abstract}

\section{ABSTRACT}

\section{AIM}

Now a day it becomes a challenge in treating proximal humerus fractures and as we know the commonest problem is shoulder stiffness. The aim was to analyse the rational and results of proximal humerus fracture fixation by various methods.

\section{MATERIAL AND METHODS}

We operated on 36 patients from 2010-2016. The common age group affected was 51-60 years. Most of the injuries were caused by domestic accidents. Neer system was used for classification. Majority of the fractures were treated with closed reduction and percutaneous fixation. Failure to reduce the fracture by closed manipulation meant we ended up with open reduction and fixation with K-wire /screw/osseous sutures.

\section{RESULTS}

The mean follow-up was 3.8 years. All fractures healed. Malunion occurred in six patients. Superficial pin tract infection, pin migration, pins loosening and avascular necrosis found only in few and that did not affect the final outcome. The functional results were analysed using Constant-Murley score. Four patients had moderate pain. Two patients had shoulder stiffness. The mean final constant score was 83 points or $89.65 \%$ of opposite normal shoulder. There is no statistically significant difference in Constant score found between different types of fractures.

\section{DISCUSSION AND CONCLUSION}

Surgical fixation of the proximal humerus fractures gives good results with least stiffness and pain free joint. This was possible because of achieving anatomical realignment and early mobilisation after stable fixation by various methods depending on the type and personality of the fracture.

\section{KEYWORDS}

Proximal Humerus, Neer, Minimal Fixation

HOW TO CITE THIS ARTICLE: Kannan K, Palaniappan M, Anbu S, et al. Rationale and results of proximal humerus fracture fixation. J. Evolution Med. Dent. Sci. 2016;5(74):5484-5488, DOI: 10.14260/jemds/2016/1241

\section{INTRODUCTION}

Fracture of Proximal Humerus is not uncommon in our orthopaedic practice. Incidence of proximal humerus fracture is increasing now. It is about 2-3\% of upper extremity fracture. An increased incidence in older patients and in women with severe osteoporosis is really a challenge in management. Majority of the injuries are due to domestic accident and road traffic accident. Mechanism of injury is indirect violence, mainly due to fall with outstretched hand. Strong muscular contraction has also been proposed as a mechanism, especially for greater tuberosity avulsion fracture.

Successful treatment of fractures of the Proximal Humerus presents a challenge for orthopaedic surgeons. Accurate

Financial or Other, Competing Interest: None.

Submission 22-07-2016, Peer Review 02-09-2016,

Acceptance 08-09-2016, Published 15-09-2016.

Corresponding Author:

Dr. Kishore Kannan,

K-101, Lasan Livings,

C-55, $10^{\text {th }}$ Cross West,

Thillai Nagar,

Tiruchirapalli-620018.

E-mail: skdortho@yahoo.co.in

DOI: $10.14260 /$ jemds/2016/1241 assessment of the fracture, patient compliance, medical comorbidities and time from injury to treatment are critical factors affecting outcome.

\section{FREQUENCY}

The proximal humerus fractures account for approximately $5 \%$ of all fractures. These fractures occur primarily in older patients (osteoporotic). Proximal Humerus fractures are a major cause of morbidity in the elderly population. As the population base ages, the incidence of these fractures will continue to increase.

\section{AETIOLOGY}

The most common mechanism for proximal humerus fractures is a fall on an outstretched hand from a standing height. In younger patients, high-energy trauma is a more frequent cause. Other mechanisms include violent muscle contractions from seizure activity, electrical shock and athletic injuries.

There has been diversity of opinion about the care of shoulder fractures with frequent controversies, because of difficulty to identify the displacement without a good radiographic view, invisible associated soft tissue injuries and diverse postoperative protocol. 
Majority of proximal humerus fracture are undisplaced and conservative treatment usually gives good or excellent results, $1,2,3$ but in a relatively small number of patients with displaced fractures, operative treatment is indicated. ${ }^{4,5}$

Treatment initially consisted of closed reduction, traction, casting and abduction splints. In the early 1930s, operative treatment for displaced fractures gained popularity, which continued in the 1940s and 1950s. Humeral head replacement for severely displaced fractures of the proximal humerus was introduced in the 1950s. In the 1970s, the AO/ASIF group popularised plates and screws for fracture fixation and humeral head prostheses were redesigned.

Various techniques of treatment have been described, but type of reduction and stabilisation of this fracture remains controversial.5-8 We reviewed the clinical and radiological results of operative treatment in a consecutive series of proximal humerus fracture.

\section{MATERIAL AND METHODS}

We operated on 36 patients with proximal humerus fractures by surgical reduction (Closed or open) and fixation (percutaneous or internal). There were 23 males and 13 females. Left shoulder was commonly involved than right.

The common age group affected was 51-60 years with mean age being 51.9 years (24-84 yrs.). Most of the injuries were caused by domestic accidents (61.1\%) and the next common was road traffic accident (28.4\%). Associated injuries occurred in 8 patients, mainly with ipsilateral clavicle fracture and fracture of the distal radius.

The Neer system ${ }^{1,2}$ was used for classification of proximal fracture by evaluating displacement of any of the four principal fragments (head, shaft, greater tuberosity and lesser tuberosity). All fractures in which no segment was displaced more than $1 \mathrm{~cm}$ or not rotated more than $45^{\circ}$ degrees were considered undisplaced and excluded from our study. The Neer classification system is based on displacement of $1 \mathrm{~cm}$ or fragment angulation of $45^{\circ}$.

\section{The type of Fracture then is divided into the following} Four Segments:

- Articular segment.

- Lesser tuberosity.

- Greater tuberosity.

- Surgical neck.

The basis for the AO/ASIF classification is predicated on disruption of the blood supply to the articular segment, increasing incidence of avascular necrosis.

According to number of segments displaced, the fractures are considered two-part, three-part and four-part fracture. There were 26 two-part fractures, 6 three-part fractures and 4 four-part fractures which includes 3 valgus impacted fractures.

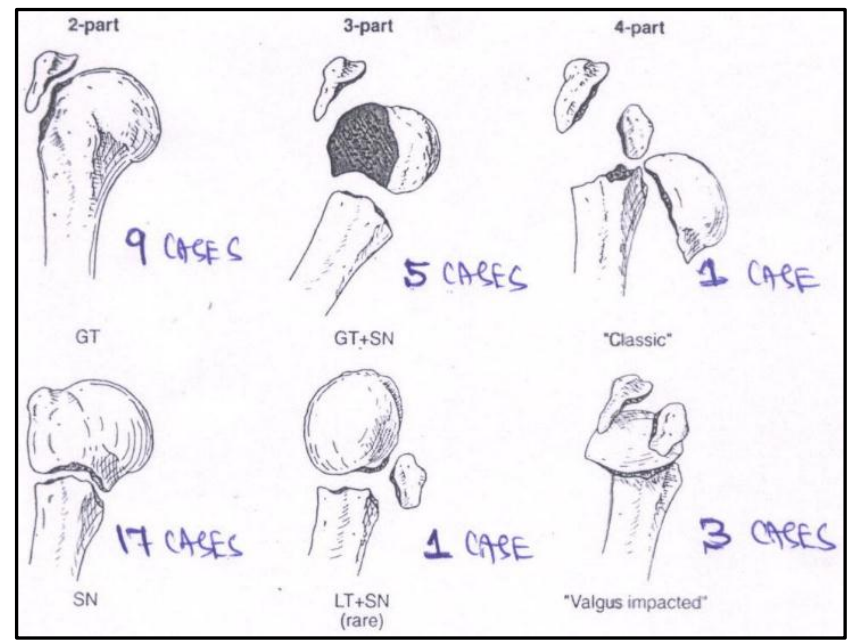

Fig. 1: Distribution of Fractures ${ }^{2}$

\section{Surgical Techniques}

All patients underwent routine radiological evaluation (AP and axillary view) and majority of the patients were examined under regional anaesthesia (supraclavicular and interscalene blocks). The fracture pattern and their behaviour during movements were assessed with $\mathrm{C}$-arm under anaesthesia to determine the type of treatment modality required. It is necessary to determine presence of associated neurovascular injury. The axillary nerve is the nerve most commonly injured in proximal humerus fracture. Sensation over the deltoid muscle region is assessed and isometric deltoid motor function is observed for any deficit and compared with the normal side for evaluation. Neurological testing for brachial plexus injuries is done as a routine in all the proximal humerus cases.

Examination of peripheral pulses is helpful to rule out associated vascular injuries. Inspect the proximal shoulder girdle for sign of arterial rupture by looking for ecchymosis and petechiae. If injury is suspected, obtain an angiogram immediately. We used various techniques of reduction and fixation based on the type of fracture and degree of displacement. Again, the personality of the fracture was studied dynamically under C-arm scan control.

Two-part greater tuberosity fractures were treated by percutaneous reduction and cannulated cancellous screw fixation if the fragment is more than $2 \mathrm{~cm}$ in size. The fragment was well-aligned and guide wires passed. Through the wires under C-arm control, two small incisions over the deltoid region were made and percutaneously cannulated screws were inserted. Open reduction was required if the fragments were small enough to pass cancellous screws and if there was comminution which prohibited screw fixation. In these cases, osseous suturing technique was used to stabilise the fracture. Two-part surgical neck, three-part fractures and four-part fractures were treated with percutaneous K-wire fixation or osseous sutures depending on the degree of comminution. 
The valgus-impacted fractures were first reduced by closed means and thereafter treated with closed reduction and percutaneous pinning. We used this technique of introducing a rasp percutaneously under $\mathrm{C}$-arm control in the lateral aspect of the proximal humerus to elevate the lateral aspect of the humeral head segment. On doing so, the greater tuberosity fragment usually reduced spontaneously. If not we apply minimal pressure on the fragment to aid the reduction and also by using the rasp to reduce the fragment through the same incision. ${ }^{3}$ The fracture was stabilised with two pins into the head and 2 pins passed through the greater tuberosity into the medial cortex.

If reduction by closed means is not achievable, open reduction was done. Deltopectoral approach or Deltoid splitting strap incision was used to reduce the fracture and the fragments were fixed with K-wire/screw/osseous sutures (No-2 Ethilon).

Routine post-operative check X-rays were taken. Patients were asked to come for regular follow-up for 3 months in regular intervals. First week for wound inspection, Second week for suture removal in cases where required and every two weeks thereafter. During all the visits, X-rays were taken to assess the fixation stability, pin migration and union signs. Physiotherapy protocol depended on the stability of the fixation. Pendulum exercises were started immediately for all patients irrespective of the type of fixation. Arm sling support was given for 5 weeks. All the percutaneous pins were removed at $5^{\text {th }}$ to $7^{\text {th }}$ weeks and vigorous physiotherapy commenced. Patients were reviewed and scoring evaluated after explaining the details of the scoring system.

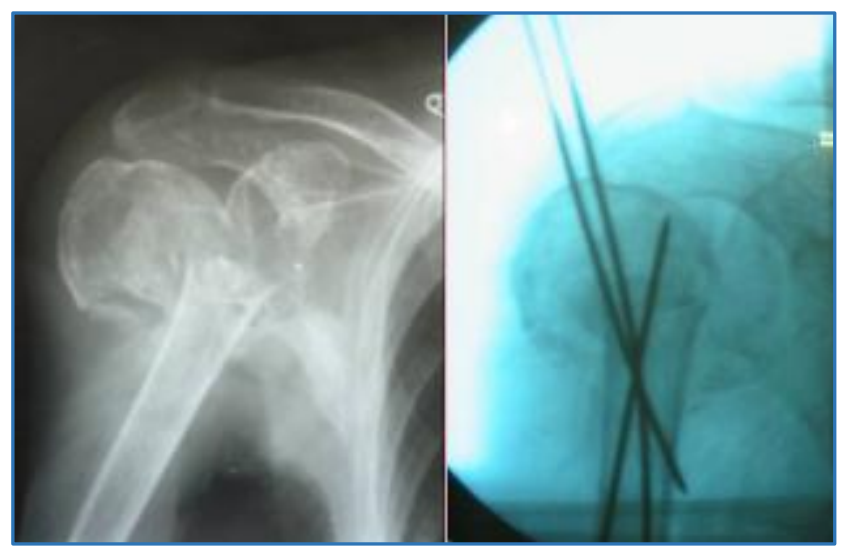

Picture 1: Fracture of Proximal Humerus Fixed with Percutaneous K-Wires

\section{RESULTS}

The follow-up range was from 2.1-5.2 years (mean - $3.8 \mathrm{yrs}$.). All the fractures united well without delayed union or nonunion. Persistent displacement of at least $1 \mathrm{~cm}$ or rotation more than $45^{\circ}$ of any one fragment is considered malunited. In our study, six fracture cases were found to be malunited under these criteria. Four of these cases were three-part fractures and two of the fractures were two-part surgical neck fractures treated with percutaneous pinning. On reassessment we found this was due to inadequate reduction in first place. The inadequate reduction was due to associated soft tissue injuries, which hamper proper reduction and the fracture pattern being more complex.
There was no incidence of any general complication in our study. Superficial pin tract infection occurred in 8 patients, which were treated conservatively with antibiotics and regular pin site care. Proximal migration of pins occurred in two patients. These patients were treated with removal of the pins.

Pin loosening occurred in three patients mainly after 3 weeks, managed with removal of the pin because of the stabilisation by the other pins. Two patients went in for resurgery because of the displacement of the fragments and migration of pin. No neurovascular complication occurred in our study. Avascular necrosis occurred in one patient with four-part fracture.

The European Society for Shoulder and Elbow Surgery (ESSES) adopted the scoring system of C Constant and A Murley. In our series, the functional results were analysed by using Constant-Murley score. ${ }^{9}$ This scoring system consists of four variables that are used to assess the function of the shoulder. The right and left shoulders are assessed separately. The SUBJECTIVE variables are pain and ADL (sleep, work, recreation/sport), which give a total of 35 points. The objective variables are range of motion and strength, which give a total of 65 points. RANGE OF MOTION: Active range of motion should always be measured as part of the Constant Score. ESSES recommends measuring range of motion with the patient sitting on a chair or bed with weight evenly distributed between the ischial tuberosities. No rotation of the upper body may take place during the examination. In the case of active motion, the patient lifts his arm to a pain free level. Note that the degree at which the pain starts determines the range of motion. If one measures the active range of motion with pain, this should be stated. The Constant score cannot then be applied beyond the initiation of pain.

The most important thing is that range of motion is performed and measured in a standardised way. In the Constant score system, there is precise information about how the points are calculated ${ }^{10-13} ; 150$ degrees of flexion give 8 points, while 151 degrees give 10 points. Strength is given a maximum of 25 points in the Constant Score. The significance and technique of strength measurement has been and continues to be the subject of much discussion.

The European Society for Shoulder and Elbow Surgery measures Strength According to the Following Method:

- A spring balance is attached distal on the forearm.

- Strength is measured with the arm in 90 degrees of elevation in the plane of the scapula (30 degrees in front of the coronal plane) and elbow straight.

- Palm of the hand facing the floor (pronation).

- The patient is asked to maintain this resisted elevation for 5 seconds.

- It is repeated 3 times immediately after another.

- The average in pound (lb) is noted.

- The measurement should be pain free. If pain is present, the patient gets 0 points.

- If patient is unable to achieve 90 degrees of elevation in the scapula plane, the patient gets 0 points. 


\begin{tabular}{|c|c|c|c|c|}
\hline $\begin{array}{c}\text { Fracture } \\
\text { Type }\end{array}$ & $\begin{array}{c}\text { No. } \\
\text { of } \\
\text { Patient }\end{array}$ & $\%$ & $\begin{array}{c}\text { Constant } \\
\text { Score } \\
\text { Points }\end{array}$ & $\begin{array}{c}\text { Opposite } \\
\text { Shoulder }\end{array}$ \\
\hline Two-part & 26 & $72.2 \%$ & 89.87 & $95.28 \%$ \\
\hline Three-part & 6 & $16.6 \%$ & 83.66 & $89.47 \%$ \\
\hline Four-part & 4 & $11.2 \%$ & 75.5 & $84.21 \%$ \\
\hline & 36 & & 83.01 & $89.65 \%$ \\
\hline \multicolumn{4}{|c|}{ Table 1: Functional Results of Our Study } \\
\hline
\end{tabular}

All the points were compared with opposite normal shoulder and the total score was corrected for age and gender.

Twenty-four patients had no pain, eight patients had mild and four patients had moderate pain only on movement. Regarding activities of daily living, all the patients were able to do their routine activities which they were doing before injury and all went back to their original job. Only four patients were not able to participate in sports and recreation satisfactorily. None of the patients had sleep disturbance and the average positioning of the arm while working was (functional external rotation) up to top of the head.

The mean constant score for two-part fractures were 89.87 points; three-part fractures were 83.66 points and four-part fractures were 75.5 points. The mean final constant score was 83 points in affected shoulder or $89.65 \%$ of opposite normal shoulder.

Six patients had malunion with little functional problem. Partial avascular necrosis was noted in one patient. The overall functional results were good and not statistically different from those without malunion.

No statistically significant difference in constant score was found between the different types of fractures. The presence of avascular neurosis and outcome were not influenced by age, gender and type of fracture.

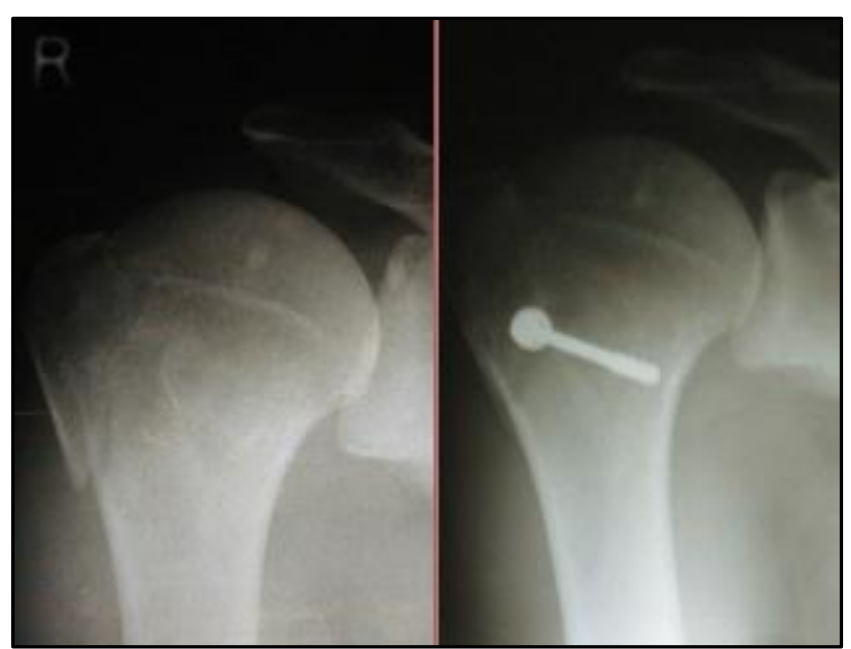

Picture 2: Greater Tuberosity Avulsion Fracture Fixed with Percutaneous Cancellous Screw Fixation

\section{DISCUSSION}

Majority of the proximal humerus fractures are undisplaced and are treated conservatively. Only in the remaining displaced fractures, operative treatment was indicated. Various modalities of treatment have been described for these fractures.
This is based upon features such as fracture morphology, age, needs of the patient, bone quality and the experience and skill of the surgeon.

Indications for operative treatment are displaced articular fractures and periarticular fractures. Type of the fracture (Eg. Displacement, Fracture orientation), bone morphology (Eg. Bone quality) and associated injuries (Eg. Soft tissue injuries around shoulder) and the patient's personality (Eg. Mental status) have a tremendous effect on specific treatment indications.

The best result is obtained if the fracture is well reduced and it is maintained well reduced until healing has occurred 5,14 and mobilisation is started at the earliest taking care that the fracture fragments move as one unit. This early mobilisation is the key, as we know the commonest problem in shoulder fracture fixation is the post-traumatic stiffness.

Aim of our study was to prevent stiffness and alleviate pain by biological stable fixation of the fragment and to move the realigned fracture as one mass at the earliest possible.

\section{Percutaneous Cannulated Cancellous Screw Fixation}

It is a good technique of fixation. ${ }^{15}$ It gives rigid fixation and the patient can be mobilised at the earliest. This is mainly used for greater tuberosity avulsion fractures.

\section{Open Osseous Suture}

It can be used for all the types of proximal humerus fractures. It has advantage of anatomical reduction and no need for implant removal at a later date. It provides stable fixation as compared with $\mathrm{K}$ wire and screw. It is an excellent technique with predictable results, but it needs surgical expertise. The technique is more commonly used for greater tuberosity avulsion fracture, three-part and four-part fractures and in cases with severe osteoporosis.

\section{K-Wire Fixation}

Percutaneous reduction and K-wire fixation is a good technique of stabilisation of proximal humerus fractures. It provides anatomical reduction and rigid fixation in majority of the fractures. Pin loosening and migration can be avoided to certain extent by using threaded wires and removal of the pins can be done as outpatient procedure. Majority of the procedures are done by closed technique. Patient with irreducible fracture can be managed by open reduction. Open reduction too gives good results. ${ }^{16,17}$ This technique commonly used for two-part surgical neck, three-part and four-part fractures.

\section{Plate and Screw Fixation}

This method is sparingly used in two-part and three-part fractures. It provides anatomical reduction and rigid fixation. Due to the stripping of soft tissues on the proximal humerus, it adds insult to the already compromised blood supply due to the soft tissue injuries ${ }^{7,8,9,14}$ and it may cause impingement pain due to hardware prominence. Removal of the plate and screws needs re-surgery and that may lead to adhesion and thereby shoulder stiffness.

\section{Prosthetic Replacement}

Prosthetic replacement is recommended for complex threepart and four-part fractures in elderly patient with osteoporosis. It should be carried out within 2 weeks after 
trauma to have a good functional outcome. Cemented stem has to be used to provide rotational stability and to maintain the height. Tuberosity must be mobilised and fixed distally with bone graft. It gives better results than humeral head resection.

In our study, we have treated 36 patients with proximal humerus fractures with various techniques of fixation. Common techniques we used are percutaneous threaded $\mathrm{K}$ wire fixation, screw fixation and osseous suturing technique. In our study, all the fractures healed without delayed union or non-union. The bone quality was an important factor in determining the final outcome of our study. ${ }^{18,19}$

Majority of our patients were younger than 65 years with good quality of bone.

Six patients had malunion, which did not affect the final outcome of the study. The mean final constant score was 83 points or $89.65 \%$ of opposite normal shoulder. There is not much of difference in functional score in various types of fractures.

To conclude, our study confirms that carefully chosen cases fixed with threaded K-wires and osseous sutures of the proximal humerus fracture gives good results with least stiffness, pain free joint and good functional outcome.

\section{REFERENCES}

1. Neer CS. Shoulder reconstruction. Philadelphia: WB Saunders Comp 1990:551.

2. Neer CS. Displaced proximal humeral fractures: part I. Classification and evaluation.J Bone Joint Surg Am 1970;52(6):1077-89.

3. Gerber $\mathrm{C}$, Werner $\mathrm{CM}$, Vienne P. Internal fixation of complex fractures of proximal humerus. J Bone Joint Surg Br 2004;86(6):848-55.

4. Kristiansen B, Kofoed H. Transcutaneous reduction and external fixation displaced fracture of the proximal humerus a controlled clinical trial. J Bone Joint Surg Br 1988;70(5):821-4

5. Resch H, Beck E, Bayley I. Reconstruction of the valgusimpacted humeral head fracture. J Shoulder Elbow Surg 1995;4(2):73-80.

6. Zyto K, Wallace WA, Frostick SP, et al. Outcome after hemiarthroplasty for three and four-part fractures of the proximal humerus. J Shoulder Elbow Surg 1998;7(2):85-9.
7. Zyto K, Ahrengart L, Sperber A, et al. Treatment of displaced proximal humeral fractures in elderly patients. J Bone Joint Surg Br 1997;79(3):412-7.

8. Schai P, Imhoff A, Preiss S. Comminuted humeral head fractures: a multicenter analysis. J Shoulder Elbow Surg 1995;4(5):319-30.

9. Constant CR, Murley AH. A clinical method of functional assessment of the shoulder. Clinical Orthopaedics and Related Research 1987;(214):160-4.

10. Constant CR. Assessment of the shoulder. In: Watson M. Surgical disorders of the shoulder. New York: Churchill Livingstone 1991;39-45.

11. Constant CR. Constant Scoring Technique for Shoulder Function. SECEC information. 1991. Nr 3.

12. Gerber C. Integrated Scoring Systems for the Functional Assessment of the Shoulder. In: Matsen F, Fu F, Hawkins (red). The shoulder: a balance of mobility and stability. Rosemont: 1992:531-50.

13. Circular to members of british shoulder and elbow society. 1997.

14. Gerber C, Hersche O, Berberat C. The clinical relevance of post traumatic avascular necrosis of the humeral head. J Shoulder Elbow Surg 1998;7(6):586-90.

15. Jaberg H, Warner JJ, Jakob RP. Percutaneous stabilization of unstable fractures of the humerus. J Bone Joint Surg Am 1992;74(4):508-15.

16. Szyszkowitz R, Seggl W, Schleifer P, et al. Proximal humeral fractures. Management techniques and expected results. Clin Ortho Rel Res 1993;(292):13-25.

17. Ko JY, Yamamoto R. Surgical treatment of complex fracture of the proximal humerus. Clin Ortho Relat Res 1996;(327):225-37.

18. Neer CS. Displaced proximal humerus fractures: part II: treatment of three-part and four-part displacement. J Bone Joint Surg Am 1970;52(6):1090-103.

19. Court-Brown CM, Garg A, McQueen MM. The translated two-part fracture of the proximal humerus: epidemiology and outcome in the older patient. J Bone Joint Surg Br 2001;83(6):799-804. 